Surface roughness of two Polyamide Material Types Used in the Manufacture of Denture Base Compared with a Type of Heat-cured

\title{
Acrylic Resin
}

\author{
Mehrdad Eghtedari, ${ }^{1}$ Saghar Ghanavati, ${ }^{2,}$ Ali Rohani, ${ }^{3}$ and Mehdi Parchami ${ }^{3}$ \\ ${ }^{1}$ Assistance Professor of Prosthodontics, Department of Prosthodontics, School of Dental Medicine, Shahid Beheshti University of Medical Sciences, Tehran, IR Iran \\ ${ }^{2}$ Resident of Prosthodontics, Department of Prosthodontics, School of Dental Medicine, Ahvaz Jundishapur University of Medical Sciences, Ahvaz, IR Iran \\ ${ }^{3}$ Dentistry Student, School of Dental Medicine, Ahvaz Jundishapur University of Medical Sciences, Ahvaz, IR Iran \\ "Corresponding author: Saghar Ghanavati, Department of Prosthodontics, School of Dental Medicine, Ahvaz Jundishapur University of Medical Sciences, Ahvaz, IR Iran. Tel: \\ +98-9166538235, E-mail: saghar.ghanavati66@gmail.com
}

Received 2017 May 15; Accepted 2017 June 12.

\begin{abstract}
Background and Objectives: Some of the disadvantages of the heat-cured acrylic resins include high porosity, high water absorption, volume changes, and a lot of residual monomer. The development of polymer chemistry produced different kinds of materials such as polyamide, Acetal resins, and etc. Recently, polyamide materials are widely used in the manufacture of denture base. Denture bases made from this material are more flexible than conventional PMMA. There is a direct relationship between surface roughness (as a result of polishing) and the retention of microbial plaque. This study compared the surface roughness of 2 polyamide materials with a heat-cure acrylic resin.

Methods: A total of 60 wax samples $(30 \times 15 \times 4 \mathrm{~mm})$ were made. For preparation of PMMA specimens, 20 of the samples were heated in the $165^{\circ} \mathrm{F}$ water bath for 9 hours. Other 40 wax samples were used for the preparation of polyamide samples (TCS and VAL), according to the factory instructions. Polyamide samples were heated for 11 minutes at $274^{\circ} \mathrm{C}-293^{\circ} \mathrm{C}$ and then, injection was done for them. After finishing and polishing, the thickness of the samples decreased to $3 \mathrm{~mm}$. Roughness was measured by a stylus profilometer (the length of the cutoff $=0.8 \mathrm{~mm}$ and speed of pen movement $0.5 \mathrm{~mm} / \mathrm{s}$ randomly in 3 regions of each sample. The t-test was used for a statistical analysis.

Results: There is a significant difference between surface roughness of heat-cure acrylic resin with polyamide materials $(\mathrm{P}<0.05)$, however there is no significant difference between surface roughness of 2 types of polyamide materials $(\mathrm{P}>0.05)$. The surface roughness of all specimens was higher than the threshold level $(0.2 \mu)$.

Conclusions: Due to the high surface roughness of polyamide materials, the use of polyamide materials cannot be recommended for the construction of permanent appliance. Surface roughness of heat-cure acrylic resin of Meliodent (PMMA) was higher than the accepted standard.
\end{abstract}

Keywords: Denture Base, Polyamide, Profilometer, Surface Roughness

\section{Background}

The introduction of acrylic resins was a big revolution in dentistry. Acrylic resins were obtained industrially from materials that were castable, packable, or injectable into the generator. This process occurred during the initial plastic phase, which can be polymerized by a chemical reaction. More acrylic resins are known as polymethyl methacrylate (PMMA) (1).

Some of the disadvantages of the heat-cured acrylic resins are high porosity, high water absorption, volume changes, and a lot of residual monomer. The development of polymer chemistry produced different types of materials such as polyamide (Nylon plastics), Acetal resins (materials with Polyoxymethylene Base), Epoxy resins, polystyrene, polycarbonate resin, and so on. All of these new types of resins are among thermoplastic materials.

The use of thermoplastic resins in dentistry has considerably grown in the last decade. The technology of manufacture of these substances is on the basis of turning these materials into plastic during the heat process (without any chemical reaction). The ability to inject the material into a generator has opened a new aperture in the technology of manufacturing of partial and full dentures (1).

Acrylic resins have been widely used in dentistry, such as the removable partial denture base, complete dentures, overdentures on dental implants or tooth- supported, or- 
thodontic appliances, stents, and surgical guides for implant placement and provisional restorations. In all of these cases, acrylic resin should have a smooth and polished surface to make the patient comfortable and maintain a healthy tissue and prevent colonization of microorganisms and plaque accumulation as well as the pigment.

Recently, polyamide materials are widely used in the manufacture of denture base. Denture bases made from this material are more flexible than conventional PMMA (2).

Since the surface roughness and thus polishing, direct impact on the reduction of the plaque retention (2) and since in this context, much research has not been done, the surface roughness of 2 types of polyamide materials from prestigious and old brands on the market has been investigated and compared with a heat-cured acrylic resin.

\section{Methods}

The 60 sections of red wax (Cavex, Holland, BV) were prepared with dimensions of $30 \times 15 \times 4 \mathrm{~mm}$. A total of 20 of these wax samples were invested to prepare the heat-cured acrylic samples by Stone gypsum (type III, Kheyzaran, Isfahan, Iran).

In the standard muffle, samples were heated in a water bath $165^{\circ} \mathrm{F}$ for 9 hours (3) and 40 wax samples to assist in the preparation of polyamide samples were sprued (TCS, TCS Partial, USA; Valplast, Valplast USA) according to the factory's instruction. In a half of muffle, stone plaster with a creamy consistency was poured. The sprued wax samples were placed in plaster. The 2 nd half of the muffle was put and from its opening, the remaining space of muffle was filled with gypsum, as well. To remove wax, samples were placed in boiling water for half an hour. Cartridges stacked by polyamide materials were placed in the special furnace for 11 minutes at a temperature of $274^{\circ} \mathrm{C}-{ }^{\circ} 293 \mathrm{C}$ and immediately muffle along with cartridge was placed on the press machine and injection was done; the clamp of the press machine was turned until the generator was filled. Then, the muffle was kept for 10 - 20 minutes at room temperature.

For finishing 20 samples of heat-cured acrylic resin, 1st, the additional edges were removed using the bur machine (Vulcanite Bur, DENTSPLY International Inc., Germany). Polishing was done by a fluffy and Tripoli wheel (Dentorium Products, USA), tin oxide, and water thoroughly (until the acrylic surface was smooth and shiny).

For finishing and polishing polyamide samples, the tools provided by the respective factory were used. For finishing polyamide samples of Valplast brand, we used Vulcanite Bur, diamond knives, pink abrasive wheels, and brown rubber wheels and then the samples were polished by industrial pomace of Acrylux 150 and brown Tripoli. The remains of Tripoli were removed by B-20 brushes and final polishing was done by Valplast's mirror-shine until the surface got smooth and glossy.

For finishing polyamide samples of TCS brand, according to the factory instructions, burs, wheels, and rubber point was used; then, using Tufted leather, an initial polishing was done and Tripoli was used to polish until the surface was smooth and shiny and the remains of Tripoli was removed by $20-B$ brush.

After finishing and polishing the samples, thickness of all samples was reduced to $3 \mathrm{~mm}$ and thus, 60 blocks with the size of $30 \times 15 \times 3 \mathrm{~mm}$ were obtained. All samples were kept in airtight bags containing $10 \mathrm{~mL}$ of water. Each sample was kept for 5 minutes in an ultrasonic bath (SONICA $1200 \mathrm{M}$, SOLTIC, Italy) and before roughness measurements, were dried by a high-pressure air pipe.

It should be noted that the preparation of all samples was carried out by a single person. Roughness parameters $\left(R_{a}, R_{z}, R_{t}\right)$ were measured by the Stylus profilometer (T-8000-C, Germany, Hommel Werke) with a micron accuracy (Cutoff height $=0.8 \mathrm{~mm}$, speed of pen movement $=0.5$ $\mathrm{mm} / \mathrm{s}$, and cutting depth $=0.03 \mathrm{~mm}$ ). Roughness parameters were measured in 3 different areas of each sample with a length of $\mathrm{mm} 10$, which were randomly chosen, and each 3 areas were considered as the average of each sample.

\section{Results}

Surface roughness of the samples was measured by Stylus Profilometer. In the following ((1 - 4) and Figures 1, 2, and 3, Central tendency parameters and Dispersion parameters of Ra, Rz, and Rt have been presented. The maximum amount of roughness index of Ra was related to Valplast $($ mean $=0.52)$ and then, TCS $($ mean $=0.48)$ and the lowest amount was related to Meliodent $($ mean $=0.31$ ).

The maximum amount of roughness index of Rt was related to Valplast $($ mean $=8.02)$ and then, $\operatorname{TCS}($ mean $=7.16)$ and the lowest amount was related to Meliodent $($ mean $=$ 3.33).

The maximum amount of roughness index of $\mathrm{Rz}$ was related to Valplast $($ mean $=4.96)$ and then, TCS $($ mean $=$ $4.60)$ and the lowest amount was related to Meliodent $($ mean $=2.44)$.

For all 3 groups of Meliodent, Valplast, and TCS there is a significant difference between roughness indices of Ra, $\mathrm{Rz}$, and $\mathrm{Rt}(\mathrm{P}<0.001)$. These differences were evaluated using the Dunnett $\mathrm{C}$ test.

In the groups of Ra, Rz, and Rt, Meliodent has shown significant differences with Valplast and TCS $(\mathrm{P}<0.05)$, however, Valplast does not have a significant difference with TCS $(\mathrm{P}>0.05)$. 
Table 1. Comparison of Distribution of Ra, Rt, and Rz Roughness Parameters for Heat-Cured Acrylic Resin of Meliodent and Polyamides of Valplast and TCS

\begin{tabular}{|c|c|c|c|c|c|c|c|c|c|}
\hline & \multirow[b]{2}{*}{ Descriptive } & \multirow[t]{2}{*}{$\mathbf{N}$} & \multirow[t]{2}{*}{ Mean } & \multirow[t]{2}{*}{ Std. Deviation } & \multirow[t]{2}{*}{ Std. Error } & \multicolumn{2}{|c|}{ 95\% Confidence Interval for Mean } & \multirow[t]{2}{*}{ Minimum } & \multirow[t]{2}{*}{ Maximum } \\
\hline & & & & & & Lower Bound & Upper Bound & & \\
\hline \multirow{4}{*}{$\mathbf{R a}$} & Meliodent & 20 & 0.3120 & 0.03778 & 0.00845 & 0.2943 & 0.3297 & 0.25 & 0.40 \\
\hline & Valplast & 20 & 0.5200 & 0.15705 & 0.03512 & 0.4465 & 0.5935 & 0.31 & 0.82 \\
\hline & TCS & 20 & 0.4850 & 0.10526 & 0.02354 & 0.4357 & 0.5343 & 0.33 & 0.68 \\
\hline & Total & 60 & 0.4390 & 0.14275 & 0.01843 & 0.4021 & 0.4759 & 0.25 & 0.82 \\
\hline \multirow{4}{*}{ Rt } & Meliodent & 20 & 3.3385 & 1.09327 & 0.24446 & 2.8268 & 3.8502 & 2.03 & 5.92 \\
\hline & Valplast & 20 & 8.0205 & 2.05664 & 0.45988 & 7.0580 & 8.9830 & 5.42 & 11.88 \\
\hline & TCS & 20 & 7.1615 & 2.62798 & 0.58763 & 5.9316 & 8.3914 & 3.20 & 10.99 \\
\hline & Total & 60 & 6.1735 & 2.86057 & 0.36930 & 5.4345 & 6.9125 & 2.03 & 11.88 \\
\hline \multirow{4}{*}{$\mathrm{Rz}$} & Meliodent & 20 & 2.4485 & 0.39283 & 0.08784 & 2.2646 & 2.6324 & 1.92 & 3.21 \\
\hline & Valplast & 20 & 4.9630 & 1.62484 & 0.36333 & 4.2025 & 5.7235 & 2.78 & 8.64 \\
\hline & TCS & 20 & 4.6000 & 1.11425 & 0.24915 & 4.0785 & 5.1215 & 2.60 & 6.14 \\
\hline & Total & 60 & 4.0038 & 1.59753 & 0.20624 & 3.5911 & 4.4165 & 1.92 & 8.64 \\
\hline
\end{tabular}

Table 2. Results of the ANOVA Test

\begin{tabular}{|c|c|c|c|c|c|c|}
\hline & & Sum of Squares & Df & Mean Square & $\mathbf{F}$ & Sig. \\
\hline \multirow{3}{*}{$\mathbf{R a}$} & Between Groups & 0.496 & 2 & 0.248 & 20.021 & 0.000 \\
\hline & Within Groups & 0.706 & 57 & 0.012 & & \\
\hline & Total & 1.202 & 59 & & & \\
\hline \multirow{3}{*}{ Rt } & Between Groups & 248.496 & 2 & 124.248 & 30.227 & 0.000 \\
\hline & Within Groups & 234.295 & 57 & 4.110 & & \\
\hline & Total & 482.790 & 59 & & & \\
\hline \multirow{3}{*}{$\mathbf{R z}$} & Between Groups & 73.890 & 2 & 36.945 & 27.461 & 0.000 \\
\hline & Within Groups & 76.684 & 57 & 1.345 & & \\
\hline & Total & 150.573 & 59 & & & \\
\hline
\end{tabular}

That is, the surface roughness of the heat-cured acrylic of Meliodent is less than polyamide materials of Valplast and TCS brands, but there is no difference between the surface roughness of 2 kinds of polyamide materials.

In all groups, Ra was higher than the standard rate $(0.2$ $\mu$ ), i.e. surface roughness of the heat-cured acrylic of Meliodent and polyamide materials of Valplast and TCS brands is more than the standard amount as dental materials used in the mouth. At-test was used for statistical analysis.

\section{Discussion}

Determining the surface roughness of materials that are used as dental prostheses, before applying them in the mouth, is important. Most of the rough surfaces can lead to tooth discoloration, and cause discomforts of patient or cause the accumulation of microbial plaque and biofilm formation. Species of bacteria and fungi are more likely to connect to the rough surfaces of denture base materials (4).
Previous studies have proposed a threshold level $(\mathrm{Ra}=$ $0.2 \mu \mathrm{m}$ ) for surface roughness of dental materials used in the mouth; roughness reduction less than this amount will not decrease plaque accumulation $(4,5)$. Due to the lack of controlled clinical studies on the threshold of roughness of PMMA and polyamide we accept the $\mathrm{Ra}=0.2 \mu \mathrm{m}$ threshold to describe the data of the study.

Detailed comparison of Ra roughness index with past studies is difficult due to reasons such as the difference between the process tested, principles of polishing used, how to measure surface roughness, and the use of different types of PMMA.

In this study, manual polishing methods were used and indicators of roughness ( $\mathrm{Ra}$ and $\mathrm{Rz}$ and $\mathrm{Rt}$ ) were measured by profilometer. In this study, the average roughness (Ra) in Meliodent acrylic was $0.31 \pm 0.008 \mu \mathrm{m}$ and in polyamide, brands of Valplast and TCS was $0.52 \pm 0.035 \mu \mathrm{m}$ and $0.49 \pm 0.023 \mu \mathrm{m}$, respectively, which had statistically significant differences $(\mathrm{P}<0.001)$. Therefore, the roughness difference of Meliodent acrylic with polyamide resins 
Table 3. Results of the Dunnett C Test

\begin{tabular}{|c|c|c|c|c|c|c|}
\hline \multirow{2}{*}{$\begin{array}{l}\text { Dependent } \\
\text { Variable }\end{array}$} & \multirow[t]{2}{*}{ (I) Group } & \multirow[t]{2}{*}{ (J) Group } & \multirow{2}{*}{$\begin{array}{c}\text { Mean Difference } \\
(I-J)\end{array}$} & \multirow[t]{2}{*}{ Std. Error } & \multicolumn{2}{|c|}{ 95\% Confidence Interval } \\
\hline & & & & & Lower Bound & Upper Bound \\
\hline \multirow{6}{*}{$\mathbf{R a}$} & \multirow{2}{*}{ Meliodent } & Valplast & $-0.20800^{\mathrm{a}}$ & 0.036 & -0.3 & -0.12 \\
\hline & & TCS & $-0.17300^{\mathrm{a}}$ & 0.025 & -0.24 & -0.11 \\
\hline & \multirow{2}{*}{ Valplast } & Meliodent & $0.20800^{\mathrm{a}}$ & 0.036 & 0.116 & 0.3 \\
\hline & & TCS & 0.035 & 0.042 & -0.07 & 0.142 \\
\hline & \multirow{2}{*}{ TCS } & Meliodent & $0.17300^{\mathrm{a}}$ & 0.025 & 0.11 & 0.237 \\
\hline & & Valplast & -0.04 & 0.042 & -0.14 & 0.072 \\
\hline \multirow{6}{*}{ Rt } & \multirow{2}{*}{ Meliodent } & Valplast & $-4.68200^{\mathrm{a}}$ & 0.521 & -6.01 & -3.36 \\
\hline & & TCS & $-3.82300^{\mathrm{a}}$ & 0.636 & -5.44 & -2.21 \\
\hline & \multirow{2}{*}{ Valplast } & Meliodent & $4.68200^{\mathrm{a}}$ & 0.521 & 3.359 & 6.005 \\
\hline & & TCS & 0.859 & 0.746 & -1.04 & 2.755 \\
\hline & \multirow{2}{*}{ TCS } & Meliodent & $3.82300^{\mathrm{a}}$ & 0.636 & 2.206 & 5.44 \\
\hline & & Valplast & -0.86 & 0.746 & -2.75 & 1.037 \\
\hline \multirow{6}{*}{$\mathbf{R z}$} & \multirow{2}{*}{ Meliodent } & Valplast & $-2.51450^{\mathrm{a}}$ & 0.374 & -3.46 & -1.56 \\
\hline & & TCS & $-2.15150^{\mathrm{a}}$ & 0.264 & -2.82 & -1.48 \\
\hline & \multirow{2}{*}{ Valplast } & Meliodent & $2.51450^{\mathrm{a}}$ & 0.374 & 1.565 & 3.464 \\
\hline & & TCS & 0.363 & 0.441 & -0.76 & 1.482 \\
\hline & \multirow{2}{*}{ TCS } & Meliodent & $2.15150^{\mathrm{a}}$ & 0.264 & 1.48 & 2.823 \\
\hline & & Valplast & -0.36 & 0.441 & -1.48 & 0.756 \\
\hline
\end{tabular}

${ }^{\mathrm{a}}$ The mean difference is significant at the 0.05 level.

Table 4. Results of the T-Test (Ra Roughness Index Compared with the Standard Threshold)

\begin{tabular}{|c|c|c|c|c|c|c|c|}
\hline \multirow[t]{3}{*}{ Group } & \multicolumn{7}{|c|}{ Test Value $=0.2$} \\
\hline & & \multirow[t]{2}{*}{$\mathbf{t}$} & \multirow[t]{2}{*}{ df } & \multirow[t]{2}{*}{ Sig. (2-Tailed) } & \multirow{2}{*}{$\begin{array}{c}\text { Mean } \\
\text { Difference }\end{array}$} & \multicolumn{2}{|c|}{ 95\% Confidence Interval of the Difference } \\
\hline & & & & & & Lower & Upper \\
\hline Meliodent & $\mathrm{Ra}$ & 13.258 & 19 & 0.000 & 0.11200 & 0.0943 & 0.1297 \\
\hline Valplast & $\mathrm{Ra}$ & 9.113 & 19 & 0.000 & 0.32000 & 0.2465 & 0.3935 \\
\hline TCS & $\mathrm{Ra}$ & 12.109 & 19 & 0.000 & 0.28500 & 0.2357 & 0.3343 \\
\hline
\end{tabular}

of Valplast and TCS brands was statistically significant $(\mathrm{P}<$ 0.05), however, the difference of roughness of polyamide materials of Valplast and TCS brands was not significant ( $P$ $>0.05)$.

$\mathrm{Ra}$, in all these materials, was higher than the threshold $(0.2 \mu \mathrm{m})$; therefore, there is the possibility for colonization of microorganisms on the surface of the denture bases made of these materials with the manual polishing situation in the laboratory. As in all previous investigations, roughness of PMMA has been clinically acceptable (4-9); probably this difference may reflect the insufficiency of manual polishing in our laboratories.

The average roughness of $\mathrm{Rz}$ and index in Rt Meliodent acrylic, polyamide of Valplast, and TCS brands had statistically significant differences $(\mathrm{P}<0.001)$. Therefore, the difference in roughness of the Meliodent acrylic resin with polyamide of brands of Valplast and TCS was statistically significant $(P<0.05)$ but the difference in roughness of polyamide in Valplast and TCS brands was not significant $(\mathrm{P}>0.05)$.

In a study to measure the roughness of the heat-cured acrylic resin and polyamide samples before and after the 


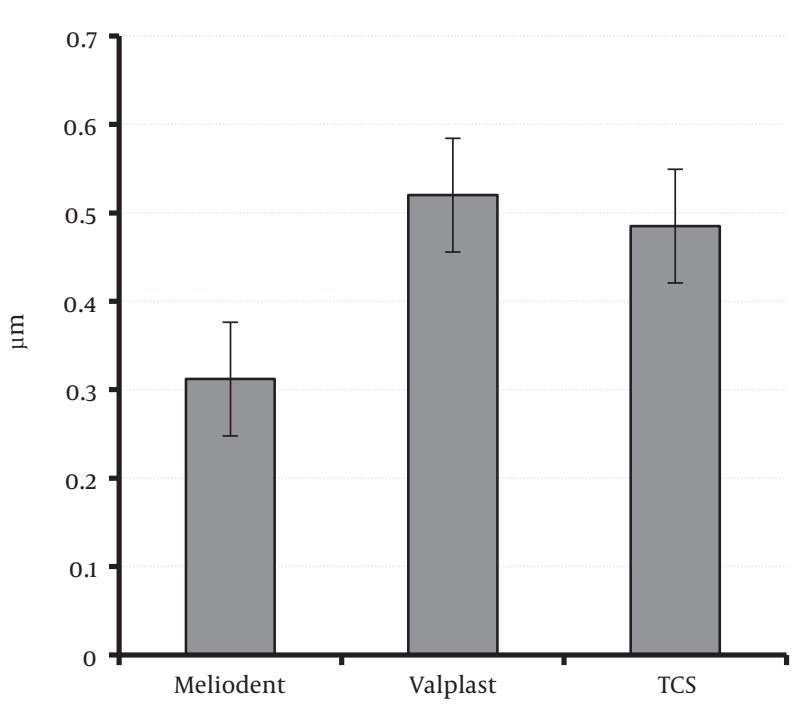

Figure 1. Mean and Standard Deviation of the Ra Index of Samples

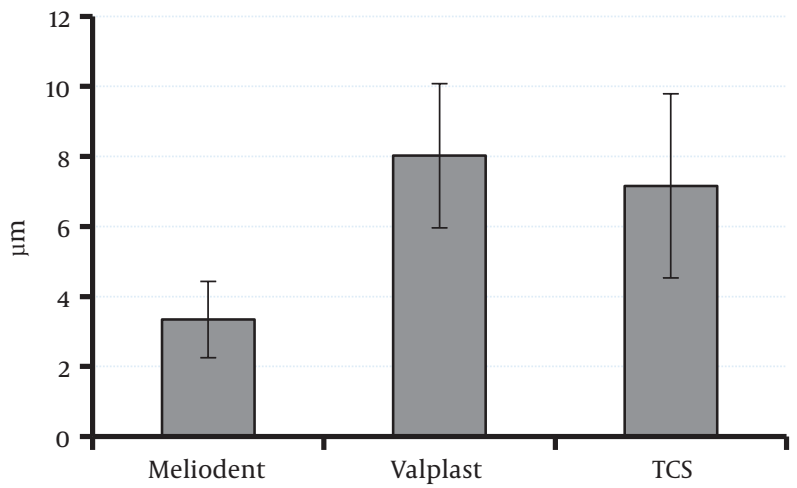

Figure 2. Mean and Standard Deviation of the Rt Index of Samples

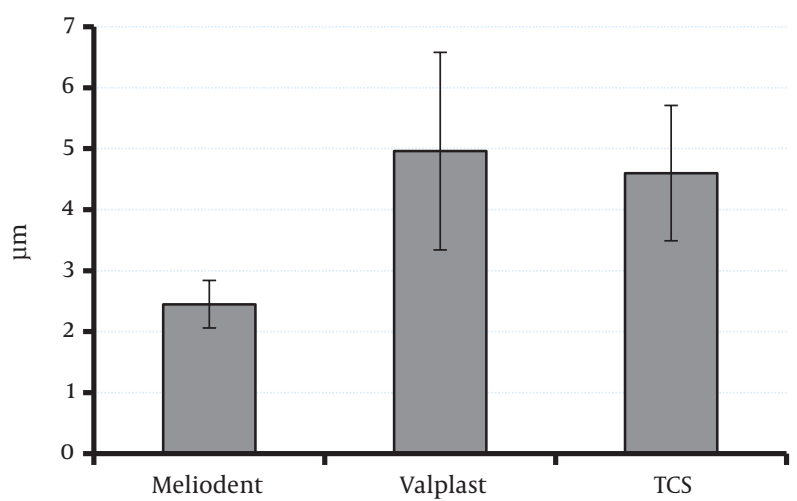

Figure 3. Mean and Standard Deviation of the Rz Index of Samples polishing, Abuzar et al. concluded that the surfaces of the samples of polyamide and PMMA were smoother 7 and 20 times, respectively; nevertheless, roughness of polyamide samples was clinically acceptable4, which in terms of comparing the roughness (to be smoother surface of PMMA samples than polyamide samples) it was similar with our study; however, in this study, surface roughness of polyamide samples is more than the standard threshold, which likely causes the insufficiency of our laboratory polishing methods.

The most probable cause of differences in roughness of polyamide with PMMA can be differences in physical characteristics. According to previous studies, due to low melting temperature polyamide, finishing, and polishing of polyamide denture bases were difficult, and suggest that accurate waxing be made to require minimal configuration of denture after making it (10)

Sometimes it has been seen that margin of samples have been worn, which can be due to the increased temperature of the surface of the samples during polishing or to be exposed to fibers within the polyamide structure. Precision in achieving a productive smooth hole after removing the wax can cause to improve the quality of the polyamide surface. Temperature and pressure of the injection in the productive hole, speed, and cooling method should be standard to achieve the desired surface quality (11).

\subsection{Conclusions}

Based on the collected data:

Due to the high surface roughness of polyamide materials, the use of polyamide materials cannot be recommended for constructing the permanent appliances, such as removed partial and fixed dentures, overdenture, gingival veneers, orthodontic appliances, etc. Surface roughness of heat-cure acrylic resin of Meliodent (PMMA) has been more accepted than the standard.

It is recommended that:

The surface roughness of the samples before and after the polishing be evaluated and compared. For standardizing the procedures of finishing and polishing, the methods of mechanical polishing and manual polishing be compared.

\section{Acknowledgments}

This article is extracted from the thesis of Mrs. Saghar Ghanavati. 


\section{References}

1. Ardelean L, Bortun C, Motoc M. Metal-free removable partial dentures made of a thermoplastic acetal resin and two polyamide resins. $\mathrm{Ma}$ teriale Plastice. 2007;44(4):345-8.

2. Al-Rifaiy MQ. The effect of mechanical and chemical polishing techniques on the surface roughness of denture base acrylic resins. Saudi Dent J. 2010;22(1):13-7. doi: 10.1016/j.sdentj.2009.12.006. [PubMed: 23960474].

3. Zarb GA, Bolender CL, Eckert SE, Jacob R, Fenton A, Mericske-Stern R Prosthodontic treatment for edentulous patients. Complete dentures and implant-supported prostheses. St. Louis: Mosby; 2004.

4. Abuzar MA, Bellur S, Duong N, Kim BB, Lu P, Palfreyman N, et al. Evaluating surface roughness of a polyamide denture base material in comparison with poly (methyl methacrylate). J Oral Sci. 2010;52(4):577-81. [PubMed: 21206160].

5. Rhonda FJ, Zarb GA, Bolender CL. Prosthodontic treatment for edentulous patients' complete dentures and implant-supported prostheses. Waxing and processing the denture, their insertion, and fallow-up. In: Bolender CL, Eckert SE, Fenton AH, Mericske-Stern R, editors. St. Louis: Mosby; 2004. $417 \mathrm{p}$.
6. Goncalves TS, Spohr AM, de Souza RM, Macedo de Menezes L. Surface roughness of auto polymerized acrylic resin according to different manipulation and polishing methods: an in situ evaluation. Angle Orthod. 2008;78(5):931-4. doi: 10.2319/080307-363.1. [PubMed: 18298208].

7. Corsalini M, Carella M, Boccaccio A, Lamberti L, Pappalettere C, Catapano S, et al. An alternative approach to the polishing technique for acrylic resin surfaces. Int J Prosthodont. 2008;21(5):409-12. [PubMed: 18950061].

8. Berger JC, Driscoll CF, Romberg E, Luo Q, Thompson G. Surface roughness of denture base acrylic resins after processing and after polishing. J Prosthodont. 2006;15(3):180-6. doi: 10.1111/j.1532849X.2006.00098.x. [PubMed:16681500].

9. Kuhar M, Funduk N. Effects of polishing techniques on the surface roughness of acrylic denture base resins. J Prosthet Dent. 2005;93(1):76-85. doi: 10.1016/j.prosdent.2004.10.002. [PubMed: 15624002].

10. Munns D. Nylon as a denture base material. Dent Pract. 1962;13:142.

11. Hargreaves AS. Nylon as a denture-base material. Dent Pract Dent Rec. 1971;22(4):122-8. [PubMed: 5291412]. 